\title{
Epidemiology of nonfatal stroke and transient ischemic attack in Al-Kharga District, New Valley, Egypt
}

\author{
Wafaa MA Farghaly' \\ Hamdy N El-Tallawy' \\ Ghaydaa A Shehata' \\ Tarek A Rageh' \\ Nabil M Abdel-Hakeem ${ }^{2}$ \\ Mohamed A Abd Elhamed' \\ Bastawy MA Al-Fawal ${ }^{3}$ \\ Reda Badry' \\ 'Department of Neurology, Faculty \\ of Medicine, Assiut University, Assiut, \\ ${ }^{2}$ Department of Neurology, Faculty \\ of Medicine, Al-Azhar University, \\ Assiut Branch, Assiut, ${ }^{3}$ Aswan Health \\ Insurance Hospital, Ministry of Health, \\ Aswan, Egypt
}

Correspondence: Reda Badry Department of Neurology and Psychiatry, Assiut University Hospitals, PO Box 71526, Assiut, Egypt Tel +20882236954 I

Fax +20882333327

Email redaalbadry02@gmail.com
This article was published in the following Dove Press journal:

Neuropsychiatric Disease and Treatment

15 November 2013

Number of times this article has been viewed

Background: Stroke is a medical emergency. Nonfatal stroke may cause permanent neurologic damage, complications, and disability. The aim of this study was to determine the epidemiology of nonfatal stroke in Al-Kharga District, New Valley, Egypt.

Methods: The total population $(62,583)$ was screened via a door-to-door study by three neurology specialists and 15 female social workers for demographic data collection. All subjects with probable stroke were subjected to a full clinical examination, neuroimaging (computed tomography and/or magnetic resonance imaging of the brain), and laboratory investigations including blood sugar, lipid profile, serum uric acid, a complete blood count, blood urea, and serum creatinine. Stroke severity and outcome were assessed using the Scandinavian Stroke Scale and Barthel Index. Carotid Doppler, echocardiography, and thyroid function tests were done in selected cases.

Results: During the study period (June 1, 2005 to May 31, 2008), 351 subjects were diagnosed as having suffered a cerebrovascular stroke at some point during their lives, yielding a total lifetime prevalence of 5.6 per 1,000 population. Of these, 156 subjects were identified as having suffered a stroke during the year from January 1 to December 31, 2007, with an incidence rate of 2.5 per 1,000. Both prevalence and incidence rates were higher in urban (5.8 per 1,000 and 2.6 per 1,000 , respectively) than rural communities ( 5.2 per 1,000 and 2.3 per 1,000 ), and were higher in males ( 6.1 per 1,000 and 2.7 per 1,000, respectively) than in females ( 5.1 per 1,000 and 2.3 per 1,000). Thrombotic stroke had the highest prevalence and incidence rates $(4.2$ per 1,000 and 1.7 per 1,000, respectively), whereas subarachnoid hemorrhage had the lowest prevalence and incidence rates $(0.03$ per 1,000 and 0.02 per 1,000$)$.

Conclusion: The prevalence of cerebrovascular accident in Al-Kharga lies in the lower range of that in developing countries, and is similar to that in industrialized countries.

Keywords: prevalence, incidence, stroke, Egypt

\section{Introduction}

Stroke is a syndrome of rapidly developing symptoms and signs of focal and at times global loss of cerebral function lasting more than 24 hours or leading to death, with no apparent cause other than one of vascular origin. It is a medical emergency and can cause permanent neurologic damage, complications, disability, and death. ${ }^{1}$ The World Health Organization has estimated that stroke caused 5.7 million deaths in 2004, and accounted for $9.7 \%$ of deaths throughout the world. ${ }^{2}$ Of these deaths, more than $85 \%$ occurred in low-income and middle-income countries. ${ }^{3}$ The prevalence of stroke is five per 1,000 population in industrialized countries, ${ }^{4}$ but ranges from $5-10$ per 1,000 in developing countries. ${ }^{5}$ The annual incidence of stroke in the general 
population is approximately two per $1,000 .^{6}$ In Europe, the MONICA (Multinational MONItoring of trends and determinants in CArdiovascular disease) Project showed that the annual incidence rates for stroke ranged from 1.0 to 2.9 per 1,000 in men and from 0.6 to 1.9 per 1,000 in women. ${ }^{7}$ In Arab countries, the annual stroke incidence was 27.5-63 per 100,000 population and prevalence was $42-68$ per 100,000 population. Ischemic stroke was the commonest subtype in all series. ${ }^{8}$ Given the worldwide differences and the observed changes in the epidemiology of stroke over time, it is important to obtain recent data. Therefore, the aim of this study was to estimate the prevalence and incidence of nonfatal stroke and transient ischemic attack in Al-Kharga District, New Valley, Egypt.

\section{Subjects and methods}

\section{Study area}

This study was done among the population of Al-Kharga District, New Valley Governorate. The New Valley represents about $44 \%$ of the area of Egypt. It is divided into three oases, ie, Al-Kharga (capital), Al-Farafra, and Al-Dakhla Districts. This area is far from the Nile Valley and has different geographic, social, economic, and cultural characteristics. The New Valley climate is dry, very cold in the winter months, and very hot (up to $49^{\circ} \mathrm{C}$ ) in the summer months, together with a wide variation in temperature during the day and night.

\section{Sample size}

The study was carried out in all inhabitants $(n=62,583)$ who had lived in the Al-Kharga District for at least 6 months at the time of the study. Of these, 32,165 (51.4\%) were males and $30,418(48.6 \%)$ were females. The distribution of the population was mainly urban $(n=44,600,71.3 \%)$, with rural inhabitants comprising only $28.7 \%(n=17,983)$.

\section{Methods}

The present work was a part of an extended project designed to study the epidemiology of major neurologic disorders, including stroke, in Al-Kharga District, New Valley, Egypt. ${ }^{9}$ It was conducted as a door-to-door survey, including every door, in three phases from June 1, 2005 to May 31, 2008.

\section{Screening and demographic data collection}

All households in Al-Kharga District were interviewed by three neurologists using a short screening questionnaire designed by the team members of the project to identify any suspected cases of stroke as well as other neurologic disorders. ${ }^{10}$ In addition, sociodemographic data were collected during the same visit by 15 female social workers.

\section{Case ascertainment}

All suspected cases of stroke were subjected to full evaluation at Al-Kharga Hospital, where a detailed history was taken and full clinical and neurologic examinations were done. Stroke severity was evaluated using the Scandinavian Stroke Scale ${ }^{11}$ and Barthel Index ${ }^{12}$ designed to assess activities of daily living in stroke patients. The Mini-Mental State Examination ${ }^{13}$ was used to evaluate the mental status of subjects suspected to have dementia.

\section{Investigations}

All subjects suspected of having had a CVA underwent neuroimaging (computed tomography scan and/or magnetic resonance imaging) of the brain at Assiut University Hospital. Computed tomography of the brain was done to diagnose recent cases and old stroke cases $(n=210)$ using a Prospeed Plus scanner (General Electric, Fairfield, CT, USA) with a $512 \times 512$ matrix. Magnetic resonance imaging of the brain was done in a selected number of patients $(n=20)$ with a normal computed tomography scan to confirm the diagnosis of a brainstem lesion or to exclude causes other than stroke using a $1.5 \mathrm{~T}$ magnetic resonance whole body system scanner (Siemens AG, Erlangen, Germany) with echo planar imaging capability.

Special investigations were carried out for certain patients at Assiut University Hospital, including extracranial carotid Doppler, electroencephalography, and echocardiography for suspected cardioembolic events. Some investigations were carried out at Al-Kharga Hospital, including electrocardiography, fasting blood sugar, lipid profile, and serum uric acid for all patients. Renal function, liver function, and thyroid function tests, urine analysis, and a complete blood count were carried out for selected patients according to their needs.

\section{Case definition and classification}

Stroke was defined in accordance with the World Health Organization criteria as "rapidly developing clinical signs of focal (or global) disturbance of cerebral function lasting more than 24 hours (unless interrupted by surgery or death) with no apparent cause other than a vascular origin". ${ }^{14}$ 
Patients with stroke were classified according to their clinical presentation and investigations into ischemic stroke (thrombotic or embolic) or hemorrhagic stroke (cerebral or subarachnoid). All patients with embolic stroke were demonstrated to have potential embolic sources by electrocardiography, echocardiography, and carotid Doppler.

\section{Ethical approval}

This study was approved by the ethics committee of Assiut University and Ministry of Health (New Valley Area Health Services). All participants gave their informed, written consent before inclusion.

\section{Statistical analysis}

Statistical Package for the Social Sciences for Windows version 12.0.1 software (SPSS Inc., Chicago, IL, USA) and Epical 2000 were used to analyze the data. The chi-square test, independent-samples $t$-test, and one-way analysis of variance followed by the post hoc test (least significant difference) were used to analyze differences in proportions between groups. The $95 \%$ confidence interval for prevalence was calculated using Excel. The odds ratio and $95 \%$ confidence interval were used to compare sex (male and female) and residence (urban and rural) by chisquare test. A level of 0.5 was chosen as being statistically significant.

\section{Results}

The lifetime prevalence rate of nonfatal stroke in Al-Kharga District was 5.6 per 1,000, and was higher in males than in females and in urban than rural inhabitants (Table 1). The total incidence of stroke during the year from January 1 to December 31, 2007 was 2.5 per 1,000, and was higher in urban than rural inhabitants (Table 2). The lifetime prevalence and incidence increased steeply with advancing age (Table 3). Total lifetime prevalence of thrombotic stroke was the highest, followed by parenchymal hemorrhage and embolic stroke (Table 4). The prevalence and incidence of stroke subtypes increased with advancing age (Table 5).

\section{Discussion}

Epidemiologic data about neurologic disorders are scant in Egypt, and most of the relevant data are derived from hospital records which are not representative of incidence and prevalence in the community. Our study was a communitybased one (door-to-door and including every door) and was carried out in Al-Kharga District, New Valley.

In the present study, the prevalence of nonfatal stroke was 5.6 per 1,000 population. This prevalence lies within the lower range of that recorded in developing countries (5-10 per 1,000$).{ }^{5}$ This result was in agreement with that found in India $^{15}(5.5$ per 1,000), but higher than that recorded in Saudi $\operatorname{Arabia}^{16}(1.8$ per 1,000$)$ and Italy $(1.4$ per 1,000$) \cdot{ }^{17}$ The high prevalence of nonfatal stroke in the study population may reflect the increased exposure to risk factors for stroke.

The recorded incidence rates from previous studies available from the Middle East and North Africa regions vary from 38.5 to 123.7 per $100,000,{ }^{18}$ indicating a crude incidence of stroke that is lower than the rate in most developed countries. ${ }^{19}$ The Middle East and North Africa have relatively younger populations, with more than $40 \%$ aged under 15 years and only $4 \%$ over the age of 65 years. ${ }^{20}$ After adjusting for age, the stroke incidence rate was also lower than the age-adjusted incidence of total stroke in other studies, mostly conducted in Western countries. ${ }^{19}$ In the present study, during the year 2007, 156 newly discovered cases of stroke were recorded among 62,583 persons. This yielded a total stroke incidence rate of 2.5 per 1,000, which is higher than in the previous studies from North Africa and the Middle East. Further, it is higher than in the study reported by Béjot et $\mathrm{al}^{21}$ in France (113.5 per $100,000)$, Corso et $\mathrm{al}^{22}$ in Italy (223 per 100,000), and Vega et $\mathrm{al}^{23}$ in Spain $(113.5$ per 100,000). Real differences in the incidence of stroke between countries are not surprising given the varied cultures and lifestyles between countries which, in turn, results in marked differences in exposure to risk factors for stroke. ${ }^{24}$ Further, a change in population demographics may play a role in changing the world map of stroke.

Table I Residence and sex-specific lifetime prevalence of cerebrovascular accident per 1,000 population

\begin{tabular}{|c|c|c|c|c|c|c|}
\hline \multirow[t]{2}{*}{ Item } & \multicolumn{2}{|c|}{ Total population $(n=62,583)$} & \multicolumn{2}{|c|}{ Urban population $(n=44,600)$} & \multicolumn{2}{|c|}{ Rural population $(n=\mid 7,983)$} \\
\hline & Cases & Prevalence/ I,000 & Cases & Prevalence/I,000 & Cases & Prevalence/I,000 \\
\hline Total & 351 & 5.6 & 257 & 5.8 & 94 & 5.2 \\
\hline Males $(n=32,165)$ & 196 & 6.1 & $142 / 22,908$ & 6.2 & $54 / 9,257$ & 5.8 \\
\hline Females $(n=30,4 \mid 8)$ & 155 & 5.1 & $1 \mid 5 / 21,692$ & 5.3 & $40 / 8,726$ & 4.6 \\
\hline
\end{tabular}

Note: Prevalence of first ever stroke was 4.9 per I,000 population (304 cases). 
Table 2 Residence and sex-specific incidence of cerebrovascular accident per I,000 in 2007

\begin{tabular}{|c|c|c|c|c|c|c|}
\hline \multirow[t]{2}{*}{ Item } & \multicolumn{2}{|c|}{ Total population $(62,583)$} & \multicolumn{2}{|c|}{ Urban population $(44,600)$} & \multicolumn{2}{|c|}{ Rural population $(17,983)$} \\
\hline & Cases & Incidence & Cases & Incidence & Cases & Incidence \\
\hline Total & 156 & 2.5 & 114 & 2.6 & 42 & 2.3 \\
\hline Males $(n=32,165)$ & 86 & 2.7 & $63 / 22,908$ & 2.8 & $23 / 9,257$ & 2.5 \\
\hline Females $(n=30,4 \mid 8)$ & 70 & 2.3 & $51 / 21,692$ & 2.4 & $19 / 8,726$ & 2.2 \\
\hline
\end{tabular}

Note: Incidence of first ever stroke was 2.2 per I,000 (140 cases) from January I to December 31, 2007.

Sex differences in stroke incidence and prevalence were also identified in this study, with higher estimates of ischemic and intracerebral hemorrhagic stroke observed in males than in females, but the difference was not statistically significant. This was in agreement with most previous studies which found a male preponderance for occurrence of stroke. A male preponderance in stroke was apparent in our study, where $55.8 \%$ of stroke cases were males, with a female predominance for the transient ischemic attack subgroup (75\%). This is in agreement with a report from Pakistan by Wasay et al, ${ }^{25}$ who found a slight difference in sex distribution, with males being more represented (51\%) than females (49\%) in their sample. It is also in agreement with a report by Goldstein et al, ${ }^{26}$ who found that stroke was more prevalent in men than in women. Further, different epidemiological studies as in Catalonia, Spain and other countries found that the incidence of strokes were higher in males than females. ${ }^{27-30}$ The predominance of affected males in the hemorrhagic group $(57.7 \%, \mathrm{n}=30 / 52)$ and ischemic group $(55.5 \%, \mathrm{n}=166 / 299)$ can be explained partially by the higher incidence of certain risk factors (hyperglycemia and hyperuricemia, and accordingly atherosclerosis) in males than in females.

Given the knowledge that risk factors associated with impaired functioning of blood vessels appear or become exacerbated with age, it is not surprising that the data collected in this study demonstrate that the incidence and prevalence of stroke in general increases with age. This is true for transient ischemic attacks, ischemic stroke, and intracerebral hemorrhage, a finding which is in agreement with other studies..$^{15,22,27}$

Table 3 Age-specific lifetime prevalence and incidence rates for cerebrovascular accident per I,000 in 2007

\begin{tabular}{lllll}
\hline $\begin{array}{l}\text { Age } \\
\text { group } \\
\text { (years) }\end{array}$ & $\begin{array}{l}\text { Cases/ } \\
\text { population }\end{array}$ & Prevalence & $\begin{array}{l}\text { Cases/ } \\
\text { population } \\
\text { in 2007 }\end{array}$ & Incidence \\
\hline$<20$ & $7 / 26,767$ & 0.26 & $1 / 26,767$ & 0.04 \\
20 to $<40$ & $18 / 20,334$ & 0.9 & $12 / 20,334$ & 0.59 \\
40 to $<60$ & $114 / 11,545$ & 9.9 & $52 / 11,545$ & 4.5 \\
$60+$ & $212 / 3,937$ & 53.8 & $91 / 3,937$ & 23.1 \\
\hline
\end{tabular}

From the comparison of incidence rates for the different subtypes of stroke in this study, it is apparent that the incidence of ischemic stroke is much higher than that of hemorrhagic stroke. This is in accordance with the findings of Corso et $\mathrm{al}^{22}$ in Italy and Béjot et $\mathrm{a}^{21}$ in France.

Table 4 shows that the prevalence of ischemic stroke (4.8 per 1,000 population) was higher, while that of hemorrhagic stroke ( 0.83 per 1,000 population) was lower than these respective subtypes in Upper Egypt (Sohag), ${ }^{28}$ where the prevalence of ischemic and hemorrhagic subtypes were 3.9 and 1.3 per 1,000 population, respectively. The higher prevalence of ischemic stroke in Al-Kharga District than in Upper Egypt (Sohag) could be attributed to the nature of the climate, with higher temperatures in Al-Kharga perhaps leading to excessive sweating, hemoconcentration, and thrombosis.

Although the annual incidence of cerebral hemorrhage (primary intracerebral and subarachnoid) in the present study was slightly lower $(0.55$ per 1,000$)$ than the respective annual incidence in Upper Egypt $(0.62$ per 1,000$),{ }^{28}$ the annual incidence of primary intracerebral hemorrhage in our study $(0.53$ per 1,000$)$ was higher than that in Upper Egypt $(0.43$ per 1,000$) .{ }^{28}$ The crude incidence of cerebral infarction, cerebral hemorrhage, and subarachnoid hemorrhage in Japan was 2.3 per $1,000,0.66$ per 1,000 , and 0.19 per 1,000

Table 4 Lifetime prevalence and incidence rates for cerebrovascular accident subtypes per I,000 in 2007

\begin{tabular}{|c|c|c|c|c|}
\hline \multirow{2}{*}{$\begin{array}{l}\text { Subtypes } \\
\text { of CVA }\end{array}$} & \multicolumn{4}{|c|}{ Total population $(n=62,583)$} \\
\hline & Cases & Prevalence & $\begin{array}{l}\text { Cases } \\
\text { in } 2007\end{array}$ & Incidence \\
\hline Ischemic & 299 & 4.8 & 122 & 1.9 \\
\hline Thrombotic & 261 & 4.2 & 105 & 1.7 \\
\hline Embolic & 34 & 0.54 & 14 & 0.22 \\
\hline TIA & 4 & 0.06 & 3 & 0.05 \\
\hline Hemorrhagic & $52 *$ & 0.83 & $34 *$ & 0.55 \\
\hline $\begin{array}{l}\text { Parenchymal } \\
\text { hemorrhage }\end{array}$ & 50 & 0.80 & 33 & 0.53 \\
\hline
\end{tabular}


Table 5 Age-specific lifetime prevalence and incidence rates for CVA subtypes per I,000 population in 2007

\begin{tabular}{|c|c|c|c|c|c|c|}
\hline \multirow[t]{2}{*}{ Age group (years) } & \multicolumn{2}{|l|}{ Thrombotic } & \multicolumn{2}{|l|}{ Embolic } & \multicolumn{2}{|c|}{ Hemorrhagic } \\
\hline & $\begin{array}{l}\text { Prevalence } \\
\text { n per } 1,000\end{array}$ & $\begin{array}{l}\text { Incidence } \\
\text { n per I,000 }\end{array}$ & $\begin{array}{l}\text { Prevalence } \\
\text { n per } 1,000\end{array}$ & $\begin{array}{l}\text { Incidence } \\
\text { n per I,000 }\end{array}$ & $\begin{array}{l}\text { Prevalence } \\
\text { n per } 1,000\end{array}$ & $\begin{array}{l}\text { Incidence } \\
\text { n per I,000 }\end{array}$ \\
\hline$<20(\mathrm{n}=26,767)$ & $3(0.11)$ & $\mathrm{I}(0.04)$ & I (0.04) & - & $3(0.11)$ & - \\
\hline 20 to $<40(n=20,334)$ & $14(0.69)$ & $8(0.4)$ & I (0.05) & I (0.05) & $3(0.15)$ & $3(0.1)$ \\
\hline 40 to $<60^{*}(\mathrm{n}=1 \mathrm{I}, 545)$ & $8 \mathrm{I}(7)$ & $35(3)$ & $8(0.69)$ & $2(0.2)$ & $22(1.9)$ & $12(1)$ \\
\hline $60+* *(n=3,937)$ & I63 (4I.4) & $61(15.5)$ & $24(6.1)$ & II (2.8) & $24(6.1)$ & $19(4.8)$ \\
\hline
\end{tabular}

Note: *Three cases of transient ischemic attack subtype were in the age group 40 to $<60$ years; **one case was in the age group $60+$ years.

Abbreviation: CVA, cerebrovascular accident.

for males, respectively, and 1.4 per 1,000, 0.39 per 1,000 , and 0.39 per 1,000 for females. ${ }^{29}$

\section{Conclusion}

The prevalence of nonfatal stroke in Al-Kharga District, New Valley Governorate, was 5.6 per 1,000, while the incidence rate was 2.5 per 1,000 . Thrombotic stroke has the highest prevalence and incidence followed by cerebral hemorrhage, embolic stroke, and subarachnoid hemorrhage.

\section{Disclosure}

The authors report no conflicts of interest in this work.

\section{References}

1. Feigin V, Carter K, Hackett M, et al. Ethnic disparities in incidence of stroke subtypes: Auckland Regional Community Stroke Study, 2002-2003. Lancet Neurol. 2006;5(2):130-139.

2. World Health Organization. Burden of Disease Statistics. Geneva, Switzerland: World Health Organization. Available from: http:// www.who.int/healthinfo/bod/en/index.html. Accessed October 3, 2013.

3. Lopez AD, Matters MD, Ezzati M, Jamison DT, Murray CJ. Global and regional burden of disease and risk factors, 2001: systematic analysis of population health data. Lancet. 2006;367(9524): 1747-1757.

4. Chong JY, Sacco RL. Epidemiology of stroke in young adults: race/ ethnic differences. J Thromb Thrombolysis. 2005;20(2):77-83.

5. Poungvarin N. Stroke in the developing world. Lancet. 1998; 352 Suppl 3:SIII19-SIII22.

6. Sacco RL, Anand K, Lee HS, et al. Homocysteine and the risk of ischemic stroke in a triethnic cohort: the Northern Manhattan Study. Stroke. 2004;35(10):2263-2269.

7. Stegmayr B, Asplund K, Kuulasmaa K, Rajakangas AM, Thorvaldsen P, Tuomilehto J. Stroke incidence and mortality correlated to stroke risk factors in the WHO MONICA Project. An ecological study of 18 populations. Stroke. 1997;28(7):1367-1374.

8. Benamer HT, Grosset D. Stroke in Arab countries: a systematic literature review. J Neurol Sci. 2009;284(1-2):18-23.

9. El Tallawy HE, Farghaly W, Metwaly N, et al. Door-to-door survey of major neurological disorders in Al Kharga District, New Valley, Egypt: methodological aspects. Neuroepidemiology. 2010;35(3): 185-190.

10. El Tallawy HN, Farghaly WM, Rageh TA, et al. Epidemiology of major neurological disorders project in Al Kharga district, New Valley, Egypt. Neuroepidemiology. 2010;35(4):291-297.

11. Lindenstrom ES, Christiansen LW, Simonsen E. [Wernicke-Korsakoff syndrome at the Rikshospitalet in 1979-1988. A retrospective study]. Ugeskr Laeger. 1991;153(40):2819-2822. Danish.
12. Mahoney FI, Barthel DW. Functional evaluation: the Barthel Index. Md State Med J. 1965;14:61-65.

13. Folstein MF, Folstein SE, McHugh PR. "Mini-mental state". A practical method for grading the cognitive state of patients for the clinician. J Psychiatr Res. 1975;12(3):189-198.

14. Broda G, Rywik S, Polakowska M, Kupsc W. Long-term Pol-MONICA-Warsaw project: pattern of blood pressure among the population and the effects of selected factors on the blood pressure level. Pol Arch Med Wewn. 1990;84(4):253-263.

15. Das SK, Banerjee TK, Biswas A, et al. A prospective community-based study of stroke in Kolkata, India. Stroke. 2007;38(3):906-910.

16. Al Rajeh S, Awada A, Niazi G, Larbi E. Stroke in a Saudi Arabian National Guard community. Analysis of 500 consecutive cases from a population-based hospital. Stroke. 1993;24(11):1635-1639.

17. D'Alessandro G, Gallo F, Vitaliano A, et al. Prevalence of stroke and stroke-related disability in Valle d'Aosta, Italy. Neurol Sci. 2010;31(2): $137-141$.

18. Tran J, Mirzaei M, Anderson L, Leeder S. The epidemiology of stroke in the Middle East and North Africa. J Neurol Sci. 2010;295(1-2): $30-40$.

19. Feigin VL, Lawes CM, Bennett DA, Barker-Collo SL, Parag V. Stroke incidence and early case fatality reported in 56 population-based studies: a systematic review. Lancet Neurol. 2009;8(4):355-369.

20. Omran AR, Roudi F. The Middle East population puzzle. Popul Bull. 1993;48(1):1-40.

21. Béjot Y, Osseby GV, Aboa-Eboulé C, et al. Dijon's vanishing lead with regard to low incidence of stroke. Eur J Neurol. 2009;16(3): 324-329.

22. Corso GE, Bottacchi G, Giardini G, et al. Community-based study of stroke incidence in the Valley of Aosta, Italy. CARe-cerebrovascular Aosta Registry: years 2004-2005. Neuroepidemiology. 2009;32(3): 186-195.

23. Vega T, Zurriaga O, Ramos JM, et al. Stroke in Spain: epidemiologic incidence and patterns; a health sentinel network study. J Stroke Cerebrovasc Dis. 2009;18(1):11-16.

24. Goldstein LB, Jones MR, Matchar DB, et al. Improving the reliability of stroke subgroup classification using the Trial of ORG 10172 in Acute Stroke Treatment (TOAST) criteria. Stroke. 2001;32(5):1091-1098.

25. Wasay M, Jafri W, Khealani B, Azam I, Hussaini A. Helicobacter pylori gastritis and risk of ischaemic stroke. J Pak Med Assoc. 2008;58(7): 368-370.

26. Goldstein LB, Adams R, Alberts MJ, et al. Primary prevention of ischemic stroke. A guideline from the American Heart Association/American Stroke Association Stroke Council: Cosponsored by the Atherosclerotic Peripheral Vascular Disease Interdisciplinary Working Group; Cardiovascular Nursing Council; Clinical Cardiology Council; Nutrition, Physical Activity, and Metabolism Council. Stroke. 2006;37(6): 1583-1633.

27. Truelsen T, Piechowski-Jóźwiak B, Bonita R, Mathers C, Bogousslavsky J, Boysen G. Stroke incidence and prevalence in Europe: a review of available data. Eur J Neurol. 2006;13(6):581-598.

28. Kandil MR, Ahmed HN, Farwez H. Incidence and prevalence of nonfatal stroke and TIA in Upper Egypt (Sohag). Egypt J Neurol Psychiatry Neurosurg. 1996;33(1):37-44. 
29. Ishikawa S, Kayaba K, Gotoh T, et al. Incidence of total stroke, stroke subtypes, and myocardial infarction in the Japanese population: the JMS Cohort Study. J Epidemiol. 2008;18(4):144-150.
30. Marrugat J, Arboix A, Garcia-Eroles L, et al. The estimated incidence and case fatality rate of ischemic and hemorrhagic cerebrovascular disease in 2002 in Catalonia. Rev Esp Cardiol. 2007;60(6):573-580.

\section{Publish your work in this journal}

Neuropsychiatric Disease and Treatment is an international, peerreviewed journal of clinical therapeutics and pharmacology focusing on concise rapid reporting of clinical or pre-clinical studies on a range of neuropsychiatric and neurological disorders. This journal is indexed on PubMed Central, the 'PsycINFO' database and CAS.
The manuscript management system is completely online and includes a very quick and fair peer-review system, which is all easy to use. Visit http://www.dovepress.com/testimonials.php to read real quotes from published authors.

\footnotetext{
Submit your manuscript here: http://www.dovepress.com/neuropsychiatric-disease-and-treatment-journal
} 